\title{
Comparison Of Optimization Of Algorithm Particle Swarm Optimization And Genetic Algorithm With Neural Network Algorithm For Legislative Election Result
}

\author{
Mohammad Badrul \\ STMIK Nusa Mandiri, Information \\ System Program \\ Jakarta, Indonesia \\ mohammad.mbl@nusamandiri.ac.id \\ Dwi Arum Ningtyas \\ STMIK Nusa Mandiri, Information \\ System Program \\ Jakarta, Indonesia \\ dwi.dnt@nusamandiri.ac.id
}

\author{
Frieyadie \\ STMIK Nusa Mandiri, Information \\ System Program \\ Jakarta, Indonesia \\ frieyadie@ nusamandiri.ac.id \\ Daning Nur Sulistyowati \\ STMIK Nusa Mandiri, Information \\ System Program \\ Jakarta, Indonesia \\ dns9321@gmail.com
}

\author{
Akmaludin \\ STMIK Nusa Mandiri, Information \\ System Program \\ Jakarta, Indonesia \\ akmaludin.akm@nusamandiri.ac.id \\ Nurajijah \\ STMIK Nusa Mandiri, Information \\ System Program \\ Jakarta, Indonesia \\ nurazizah6878@gmail.com
}

\begin{abstract}
An Election is one of the characteristics of a country that uses the democratic system. One of the countries that embrace democratic system is the country of Indonesia. Elections or commonly called the democratic party held in Indonesia aims to choose the leadership of both the President and Vice President, members of the House of Representatives, Regional Representatives Council level one and level II, and the Regional Representatives Council. Research relating to the election had been conducted by researchers is using decision tree method or by using a neural network. The method used was limited without doing optimization method for the algorithm. In this study, researchers will conduct research focusing on the optimization using genetic algorithm optimization and particle swarm optimization algorithm with the aid of neural network algorithms. After testing the two models of neural network algorithms and genetic algorithms are the results obtained by the neural network algorithm optimization particle swarm optimization algorithm accuracy value amounted to $98.85 \%$ and the AUC value of 0.996. While the neural network algorithm with genetic algorithm optimization accuracy values of $93.03 \%$ and AUC value of 0.971 .
\end{abstract}

Keywords-General Election, Neural Network Algorithm, Particle Swarm Optimization, Genetic Algorithm.

\section{INTRODUCTION}

The Elections (Election) is one of the characteristics of a democratic country in the world. Indonesia is one of the world's most democratic systems. to make this happen, one of them is seen during a democratic party to elect a future leader of the nation who will represent the people sitting in parliament through the general election. General Election is a means of implementing the sovereignty of the people within the unitary state of the Republic of Indonesia based on
Pancasila and the 1945 Constitution [1]. The Election is a very important tool for the implementation of a democratic political system. Therefore, it is not surprising that many countries that want to be called a democratic state use elections as a mechanism to build legitimacy. Election aims to elect members of DPR, Provincial DPRD, and Regency or Municipal DPRD which are implemented with a proportional system [1]. With a direct election system and a large number of parties, legislative elections provide a great opportunity for the people of Indonesia to compete to become members of the legislature.

Methods of predicting election results have been conducted by researchers [2] predicting election results using the Bayesian Estimator method. Of the several methods used to conduct research in the field of elections, the method used is only limited to the method alone without optimizing for the algorithm. The use of optimization in research in the field of data mining is helpful to know the accuracy of the data as an option to improve the performance of the data. In this research, the researcher will do research which focuses on data optimization by using optimization algorithm that is the genetic algorithm and particle swarm optimization method with help of neural network algorithm. After testing with two models of neural network algorithm and genetic algorithm, the result is neural network algorithm with optimization algorithm particle swarm optimization accuracy value of $98,85 \%$ and AUC value equal to 0,996 . While the algorithm neural network with genetic algorithm optimization accuracy value of 93.03\% and AUC value of 0.971 .

\section{RELATED WORK}


Elections are one of the main pillars of a democracy, if not the ultimate. The centrality of electoral positions in distinguishing a democratic political system is not evident from some of the definitions put forward by some researchers. One of the earliest modern conceptions of democracy proposed by Joseph Schumpeter and later known as the Schumpeterian school places the holding of free and regular elections as the main criterion for a political system to be called a democracy. In a democracy, elections are one of the main pillars for electing leaders who will represent the people to sit in government ranging from second-level DPRD members, Level I DPRD, DPR RI and DPD.

In the contemporary democratic treasury, electoral positions gain reinforcement. Academic studies on democracy recognize two major categories of meaning, namely the conception of minimalism and maximalism. Minimalist or procedural democracy applies to political systems that carry out regular leadership changes through a free, open and electoral mechanism involving universal voting masses. While the concept of the maxim is the implementation of elections is not enough for a political system to get a degree of democracy because this concept requires respect for wider civil rights. Elections in Indonesia are divided into two parts, namely [3]:

1. New Order elections

The election system is proportionally impure, which means that the number of seat determinations is not determined by the population but also based on the administration area. New Order elections began in 1955 as the first elections held in the country of Indonesia.

It is said to be a reformation election due to the election process in 1999 before the end of elections in 1997. The elections of this reformation era began because the 1997 election products were considered by governments and other institutions not to be trusted.

The electoral system of DPR / DPRD based on the provisions of Act No. 10 of 2008 Article 5 paragraph 1 of the system used in the legislative election is a proportional system with an open list, the DPD election system implemented with the district system has many representatives of Law number 10 of 2008 article 5 paragraph 2. According to Law no. 10 the year 2008, Participant election of a member of DPR / D is political party participating in General Election, while DPD member election member is individual. Electoral political parties may nominate as many as $120 \%$ of the seats contested in every democratic and open election area and may nominate candidates with regard to women's representation of at least 30\%. Political Parties Participants in the General Elections shall be obligated to submit a list of candidates by sequence number (to obtain the Chair). Therefore, in terms of a nomination of Law No. 10, the year 2008 adopted a system of candidate list closed.

Law No. 10 the year 2008 adopts a proportional system with an open list. the proportional system refers to the seat-sharing formula and/or the determination of the elected candidate, each political party participating in the election gets a proportional seat with the number of valid votes obtained.
The application of a proportional formula begins with calculating the number of voter divisors (BPP), that is, the total number of valid votes obtained by all political parties participating in an election in an electoral district divided by the number of seats contested in the electoral district.

\section{METHOD}

Research is seeking through a methodical process to add to the knowledge itself and with others [16], by the discovery of facts and unusual insights. Another notion, research is an activity that aims to make an original contribution to science [16].

This research is experimental research with research method as follows

\subsection{Data collection}

In collecting data explained about how and from which the data in this study obtained, there are two types of data collection, namely primary data collection and secondary data collection. Primary data is data collected first to see what really happened. Secondary data is data previously made by someone either published or not (Kothari, 2004). In the primary data collection in this study using the method of observation and interview, using data related to the election in 2009. Data obtained from the KPUD Jakarta is the election data in 2009 with the amount of data as much as 2268 records, consisting of 11 variables or attributes. Any variables used are party serial number, party name, a legal vote of the party, a serial number of candidate, a name of a candidate, gender, administration city, election area, legal candidate, number of seat acquisition. While the variable goal is the election results.

\subsection{Preliminary data processing}

The amount of initial data obtained from data collection is as much as 2,268 data, but not all data can be used and not all attributes are used because it must go through several stages of initial processing of data (preparation data). To obtain quality data, several techniques are performed as follows [15]:

a. Data validation, to identify and remove odd data (outlier/noise), inconsistent data, and incomplete data (missing value).

b. Data integration and transformation, to improve the accuracy and efficiency of the algorithm. The data used in this paper is categorical. Data is transformed into Rapidminer software. The categorical attribute table is shown in Table 3.2. c. Data size reduction and discretization, to obtain the data set with the number of attributes and records are less but informative.

\subsection{Neural Network Algorithm}

The Neural network is an information processing system that has characteristics resembling human biological neural network. Neural network is defined as a computational system in which architecture and operations are inspired by the knowledge of biological neurons in the brain, which is one 
of the artificial representations of the human brain that always tries to stimulate the learning process of the human brain [4] Neural networks are based on human neural models but with simpler parts. The smallest component of a neural network is a unit or commonly called a neuron in which the neuron will transform the information received into another neuron [5].

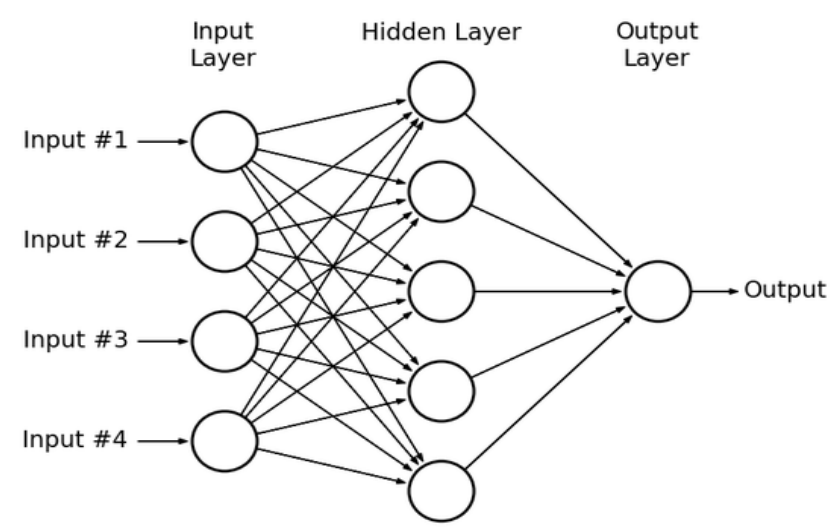

Source: [6]

Figure 1 Neural network model

The Neural network consists of two or more layers, although most networks consist of three layers: an input layer, hidden layer, and output layer [6]. The Neural network approach is motivated by biological neural networks. Roughly speaking, a neural network of a set is connected to the input/output unit [7], where each connection has a weight associated with it. Neural networks have several properties that make them popular for clustering [8]. First, the neural network is a parallel and distributed inherent processing architecture. Second, the neural network learns by adjusting the weights of interconnection with data, This allows the neural network to "normalize" the pattern and act as a feature (attribute) extractors for different groups. Third, the neural network processes numerical vectors and requires an object pattern to be represented by a quantitative feature only [9]

The Neural network consists of a collection of nodes (neurons) and relations. There are three types of nodes (neurons) namely, input, hidden and output. Each relation connects two nodes with a certain weight and there is also a direction indicating the flow of data in the process [6]. The ability of the human brain to remember, calculate, generalize, adaptation, is expected neural network can mimic the ability of the human brain. Neural networks try to imitate the structure/architecture and workings of the human brain so that it is expected to and can replace some human work. Neural network is useful for solving problems related to pattern recognition, classification, prediction and data mining [5]

The node input is at the first layer in the neural network. In general, each input node represents an input parameter such as age, gender, or income. A Hidden node is a node in the middle. This hidden node receives input from the input node on the first layer or from the hidden node of the previous layer. Hidden nodes combine all entries based on the weights of connected, calculate, and provide output for the next layer. Output nodes present predicted attributes [6].

Each node (neuron) in a neural network is a processing unit. Each node has multiple inputs and an output. Each node combines several input values, performs calculations, and generates an output value (activation). In each node, there are two functions, namely a function to combine input and activation functions to calculate the output. There are several methods for combining inputs such as weighted sum, mean, max, OR logic, or AND logic [6]. And some activation functions that can be used are Heaviside (threshold), step activation, piece wise, linear, Gaussian, sigmoid, hyperbolic tangent [9].

One of the advantages of using a neural network is that the neural network is strong enough with respect to the data. Because the neural network contains many nodes (artificial neurons) with weights assigned to each connection.

The neural network algorithm has other characteristics such as [4]

1. Inputs can be either discrete or real value that has many dimensions.

2. The output is a vector consisting of several discrete or real values

3. Can know the problem in a black-box, with only know the value of input and output only.

4. Able to handle learning to data that has noise (noise).

5. The shape of the target instructional function is unknown because it is simply the weight of the input value of each neuron.

6. Because it has to change a lot of weight value in the learning process, then the learning time becomes longer, so it is not suitable for problems that require fast time in learning.

7. The Neural network of artificial learning results can be executed appropriately.

The most popular algorithm in the neural network algorithm is the backpropagation algorithm. The backpropagation training algorithm or one that translates into backward propagation was first formulated by Paul Werbos in 1974 and popularized by Rumelhart with McClelland for use on neural networks. The backpropagation mode was originally designed for neural network feedforward, but in its development, this method was adapted for learning in other neural network models [4]. One supervised training method on a neural network is the backpropagation method, where the feature of this method is to minimize errors in output generated by the network.

Backpropagation algorithm method is widely applied widely. backpropagation has been successfully applied in various fields, including financial fields, handwriting recognition, voice recognition, control systems, image processing. backpropagation has become one of the most 
powerful computing methods. The backpropagation algorithm has a very simple relation that is: if the output gives the wrong result, then the weight is corrected so that its error can be minimized and the next network response is expected to be close to the correct value. The algorithm is also capable of fixing the weigher in the hidden layer.

Initial initialization of backpropagation network weights consisting of input layer, hidden layer, and output layer [4]. Backpropagation training stage is a step to train a neural network that is by making a weigh change (the connection between layers that form the neural network through each unit). While solving the problem will be done if the training process has been completed, this phase is called the phase of mapping or testing/testing process.

The learning steps in the backpropagation algorithm are as follows [10]:

1. Initialize network weights randomly (usually between 0.1 to 1.0 )

2. For each data in the training data, calculate the input for the node based on the input value and the current network weight, using the formula:

Input $j=\sum_{\mathrm{i}=1}^{n} o_{i} w_{\mathrm{i} j}+{ }^{\theta_{\mathrm{j}}}$

3. Based on input from step two, then generate output. to a node using sigmoid activation function:

output $=\frac{1}{1+e-\text { input }}$

4. Calculate the Error value between the predicted value and the real value using the formula:

Error $_{j}=$ output $_{\hat{j}}\left(1-\right.$ output $\left._{j}\right) \cdot\left(\right.$ target $_{j}-$ output $\left._{j}\right)$

5. After the Error value is calculated, then it is reversed to the previous layer (backpropagation). To calculate the Error value on the hidden layer, use the formula:

Error $_{j}=$ Ouput $_{j}\left(1-\right.$ Output $\left._{j}\right) \sum_{k=1}^{n}$ Error $_{k} W_{j k}$

6. The Error value generated from the previous step is used to update the relation weights using the formula:

$W_{i j}=W_{i j}+/$. Error $_{j}$. Output $_{i}$

\subsection{Particle Swarm Optimization Algorithm}

Feature Selection is closely related to dimension reduction issues where the objective is to identify features in the data set-equally important, and to remove other features such as irrelevant and excessive information and the accuracy of their enhanced future selection. The reduction of dimensions is done by minimizing the losses that can occur due to loss of some information. The purpose of dimensional reduction in the domain of data mining is to identify the smallest cost at which data mining algorithms can keep the error rate below the boundary of the efficiency line [11].

The feature selection problem refers to the selection of appropriate features that should be introduced in the analysis to maximize the performance of the resulting model. Feature selection is a computation process, which is used to select a feature set that optimizes evaluation steps that represent feature quality [12].

A feature selection algorithm is characterized by a strategy used to locate the appropriate subset of features, feature selection process, evaluation measures used to assess feature quality and interaction with the classification method used to develop the final model [11]. One of the most commonly used methods is the Particle swarm optimization method.

Particle swarm optimization can be assumed as a group of birds in search of food in a region. The bird does not know where the food is, but they know how far the food is, so the best strategy to find the food is to follow the nearest bird from the food [12].

Similar to the genetic algorithm (GA), the Particle swarm optimization performs a search using the population (swarm) of the individual (particles) to be updated from the iteration. Particle swarm optimization has several parameters such as position, speed, maximum speed, acceleration constant, and weight of inertia. Particle swarm optimization has more comparison or even superior performance search for many optimization problems with faster and more stable convergence rate [13].

To find the optimal solution, each particle moves towards its previous best position and the best position globally. For example, the ith particle is expressed as: $x i=$ (xi1, xi2, ... xid) in the d-dimensional space. The previous best position of the ith particles is stored and expressed as pbesti $=$ (pbesti, 1 , pbesti, 2, ... pbesti, d). The best particle index among all the particles in the group herd is expressed as gbestd. Particle velocity is expressed as: vi $=(v i, 1$, vi, $2, \ldots$. $v i, d)$. Modification of particle velocity and position can be calculated using the current velocity and pbesti distance, gbestd as shown in the following equation:

vi $*, d=w * v i, d+c 1 * R *($ pbesti, d - xi, d) $+\mathrm{c} 2 * \mathrm{R} *$

(gbestd - xi, d)

xid $=x i, d+v i, d$.

Where:

$\mathrm{Vi}, \mathrm{d}=$ The speed of the $\mathrm{i}$-th particles in the i-iteration

$\mathrm{w}=$ Inertial weight factor

$\mathrm{c} 1, \mathrm{c} 2=$ acceleration constants (learning rate)

$\mathrm{R}=$ Random number $(0-1)$

$\mathrm{Xi}, \mathrm{d}=$ The current position of the ith particle in the i-iteration

pbesti $=$ Best previous position of the i-particles

gbest $=$ The best particle among all the particles in a group or population

$\mathrm{n}=$ Number of particles in the group

$\mathrm{d}=$ Dimension 
Equation (6) calculates the new velocity for each particle (potential solution) based on the previous velocity $(\mathrm{Vi}$, $\mathrm{m})$, the location of the particle where the best fitness value has been achieved (pbest), and the global population location (gbest for global version, lbest for local version ) or local neighborhood on localized algorithm where the best fitness value has been reached.

Equation (7) updates the position of each particle in the solution space. Two random numbers $\mathrm{c} 1$ and $\mathrm{c} 2$ are selfgenerated. The heavy use of $w$ inertia has provided increased performance in a number of applications. The result of particle calculations is particle velocity between intervals $[0,1][13]$.

\subsection{Genetic Algorithm}

The genetic algorithm is a heuristic search algorithm based on the mechanism of biological evolution. The diversity in biological evolution is a variation of the chromosomes between individual organisms. This chromosome variation will affect the rate of reproduction and the level of ability of the organism to survive [14]. Basically, there are 4 conditions that greatly affect the evaluation process, namely as follows:

a. The ability of an organism to reproduce

b. The presence of a population of reproductive organisms

c. The existence of organisms in a population

d. Differences ability to survive.

A stronger individual (fit) will have a survival rate and a level higher reproduction when compared with fewer fit individuals. Over a period of time (often referred to as generations), the population as a whole will contain more life-sustaining organisms [14].

In the genetic algorithm, the search technique is carried out simultaneously on a number of possible solutions known as the population. Individuals in one population are called chromosomes. This chromosome is a solution that is still a symbol. The initial population is randomly constructed, while the next population is the result of the evolution of chromosomes through an iteration called the generic term. In each generation, the chromosomes will go through the evaluation process using a measuring instrument called a fitness function. The fitness value of a chromosome will show the quality of the chromosome in that population. The next generation known as the term child (offspring) is formed from a combination of 2 current generation chromosomes that act as the parent by using crossover operator. In addition to the cross-carrier, a chromosome may also be modified using a mutation operator. The new generation population is formed by selecting the fitness value of the offspring, and rejecting the other chromosomes so that the population size (number of chromosomes in a population) is constant. After doing various generations, then this algorithm will converge to the best chromosome of life [14].

Suppose $\mathrm{P}$ (generation) is the populace of a generation, then a simple genetic algorithm consists of the following steps:

Step 0: initialization

Assume that the data is encoded in a string of bits ( 1 and 0$)$. Determine the probability of crossover or pc Crossover rate and the probability of a mutation or muta mutation rate. Typically, pc is selected to be quite high (eg, 0.7), and pm is chosen very low (eg, 0.001)

Step 1: The selected population, consisting of a set of $n$ chromosomes each length i.

Step 2: match the $\mathrm{f}(\mathrm{x})$ calculated for each chromosome in the population.

Step 3: repeat the following steps until $\mathrm{n}$ offspring have been generated

Step 3a: Selection. Using the values of the fitness function $\mathrm{f}$ (x) of step 2, specifying the selection probability for each chromosome with higher fitness gives a higher probability of selection. The usual term for the way this probability is assigned is the roulette wheel method. For each chromosome $\mathrm{xi}$, find the proportion of these fitness chromosomes for total fitness to infer over all chromosomes. That is, finding $f\left(\mathrm{x}_{\mathrm{i}}\right)$ $/ \sum_{i} f\left(\mathrm{x}_{\mathrm{i}}\right)$ and assigning this proportion to be the probability of choosing that chromosome to be the parent. Then select a pair of chromosomes to be a parent, based on probability. Let the same chromosome have the potential to be chosen to be a parent more than once. Allowing chromosomes to pair with itself will produce copies of chromosome trees that are to a new generation. If analysts are concerned converging to local optimum too quickly, maybe the couple should not be allowed.

Step 3b: Crossover. Select randomly selected locus (crossover point) for crossover place. Then, with pc probability, do a crossover with the parent selected in step 3a: thus forming two new breeds. If the crossover is not done, copy two exact copies of the parent to be passed on to the new generation.

Step 3c: Mutations. With pm probability, mutate in each of the two offspring at each locus point. The chromosomes then take their place in the new population. If $\mathrm{n}$ is odd, discard one new chromosome randomly.

Step 4: New chromosome population replaces the current population

Step 5: Check if the termination criterion has been met. For example, is the average fitness change from generation to generation smaller? If convergence is reached, stop and report the results, otherwise go to step 2 .

\subsection{K-Fold Cross Validation Testing}

Cross-Validation is a validation technique by dividing data randomly into $\mathrm{k}$ section and each part will be classified [7]. Using cross-validation will be experimental as much as $\mathrm{k}$. The data used in this experiment is training data to find the overall error rate value. In general, the test $\mathrm{k}$ is performed 10 times to estimate the accuracy of estimation. In this study, the value of $\mathrm{k}$ used is 10 or 10 -fold Cross-Validation. 


\begin{tabular}{|c|c|c|c|c|c|c|c|c|c|}
\hline \multicolumn{10}{|c|}{ DATA SET } \\
\hline Split 1 & Split 2 & \begin{tabular}{|l|} 
Split 3 \\
\end{tabular} & Split 4 & Split 5 & Split 6 & \begin{tabular}{|l|} 
Split \\
\end{tabular} & \begin{tabular}{|l|} 
Split 8 \\
\end{tabular} & Split 9 & Split 10 \\
\hline \multicolumn{9}{|c|}{ Training } & Test \\
\hline \multicolumn{8}{|c|}{ Training } & Test & \\
\hline \multicolumn{7}{|c|}{ Training } & Test & & \\
\hline \multicolumn{6}{|c|}{ Training } & Test & & & \\
\hline \multicolumn{5}{|c|}{ Training } & Test & & & & \\
\hline & & & & Test & \multicolumn{4}{|c|}{ Training } & \\
\hline & & & Test & \multicolumn{5}{|c|}{ Training } & \\
\hline & & Test & \multicolumn{6}{|c|}{ Training } & \\
\hline & Test & \multicolumn{7}{|c|}{ Training } & \\
\hline Test & & & & & Training & & & & \\
\hline
\end{tabular}

Source: [7]

Figure 2. Illustration 10 Fold Cross Validation

Figure 2 shows that each trial will use one data test and k-1 part will be training data, then the data testing will be exchanged with one training data so that for each experiment will get different data testing.

\subsection{Confusion Matrix}

Confusion matrix provides the decisions obtained in training and testing, confusion matrix provides an assessment of the classification performance based on objects correctly or false [9]. Confusion matrix contains actual information (actual) and predicted (predicted) on the classification system. The following table explanation about the confusion matrix.

TABLE I

CONFUSION MATRIX

\begin{tabular}{|c|l|c|c|}
\hline Classification & \multicolumn{3}{|l|}{ Predicted Class } \\
\hline \multirow{4}{*}{ Observed Class } & & Class = Yes & Class = No \\
\cline { 2 - 4 } & Class = Yes & $\begin{array}{c}\text { A } \\
\text { (True Positif-tp) }\end{array}$ & $\begin{array}{c}\text { B } \\
\text { (False negatif- } \\
\text { fn) }\end{array}$ \\
\cline { 2 - 4 } & Class = No & $\begin{array}{c}\text { C } \\
\text { (False positif- }\end{array}$ & $\begin{array}{c}\text { D } \\
\text { (true } \\
\text { negative-tn) }\end{array}$ \\
\hline
\end{tabular}

Source: [9]

Information:

True Positive $(\mathrm{tp})=$ positive proportion in the data set that is classified positively

True Negative $(\mathrm{tn})=$ negative proportion in the data set that is classified negative

False Positive $(\mathrm{fp})=$ negative proportion in potentially classified data sets

FalseNegative $(\mathrm{fn})=$ negative proportions in data sets that are classified negatively

Here is the equation of confusion matrix model:

The accuracy value (acc) is the proportion of the correct number of predictions.

Can be calculated using the equation: $\mathrm{acc}=(\mathrm{tp}+\mathrm{tn}) /(\mathrm{tp}+\mathrm{tn}+\mathrm{fp}+\mathrm{fn})$

Sensitivity is used to compare the proportion of tp to positive tuples, which is calculated using the equation:

Sensitivity $=\mathrm{tp} /(\mathrm{tp}+\mathrm{fn})$

Specificity is used to compare the proportion of th to negative tuples, which is calculated using the equation:

Specificity $=\operatorname{tn} /(\mathrm{tn}+\mathrm{fp})$

PPV (positive predictive value) is the proportion of cases with a positive diagnosis, calculated using the equation:

$\mathrm{PPV}=\mathrm{tp} /(\mathrm{tp}+\mathrm{fp})$

NPV (negative predictive value) is the proportion of cases with a negative diagnosis, calculated using the equation:

$\mathrm{NPV}=\mathrm{tn} /(\mathrm{tn}+\mathrm{fn})$

\subsection{ROC Curve}

The ROC Curve (Receiver Operating Characteristic) is another way to evaluate the accuracy of the classification visually [15]. An ROC graph is a two-dimensional plot with a false positive proportion (fp) on the $\mathrm{X}$ axis and a true positive proportion (tp) on the $\mathrm{Y}$ axis. Point (0.1) is a perfect classification of all positive and negative cases. The false positive value is none $(\mathrm{fp}=0)$ and the true positive value is high $(\mathrm{tp}=1)$. Point $(0,0)$ is a classification that predicts each case to be negative $\{-1\}$, and point $(1,1)$ is a classification that predicts each case to be positive $\{1\}$. The ROC graph illustrates the trade-off between benefits ('true positives') and cost ('false positives'). Here are two types of curve ROC (discrete and continuous).
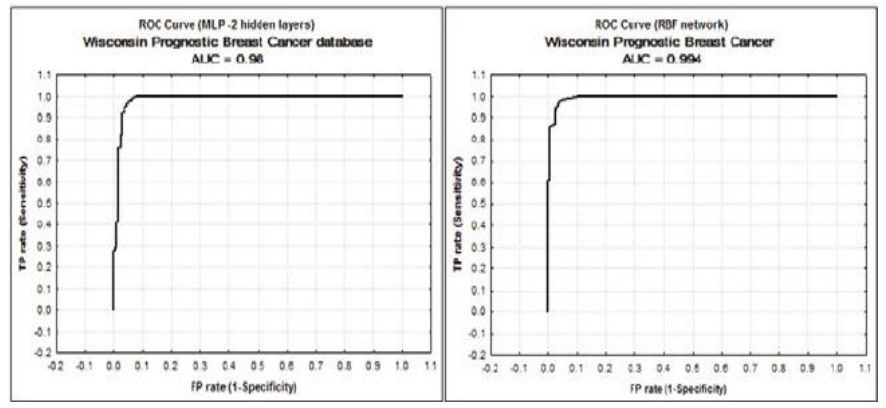

Source: [9]

Figure 3. ROC graph (discrete and continuous)

In Figure 3, the diagonal line divides the ROC space, ie:

(a) points above the diagonal line is a good classification result.

(b) the point below the diagonal line is a poor classification result.

It can be concluded that one point on the ROC curve is better than the other if the direction of the transverse line from the lower left to the top right in the graph. The level of accuracy can be diagnosed as follows [9]

Accuracy $0.90-1.00=$ Excellent classification

Accuracy $0.80-0.90=$ Good classification

Accuracy $0.70-0.80=$ Fair classification

Accuracy $0.60-0.70=$ Poor classification

Accuracy $0.50-0.60=$ Failure 


\section{EXPERIMENT RESULT}

\subsection{Neural Network Method}

The neural network algorithm is an algorithm for supervised training and is designed for operations on multilayered feed forward. The neural network algorithm can be described as follows: when the network is given an input pattern as a training pattern then the pattern goes to the units in the hidden layer to be forwarded to the outermost layer units. The best results of the experiment were with accuracy produced at 98.50 and the AUC of 0.982. From the best experiments above we get the neural network architecture by generating six hidden layers with seven input layer attributes and two output layers. The neural network architecture image is shown in Figure 4 below:

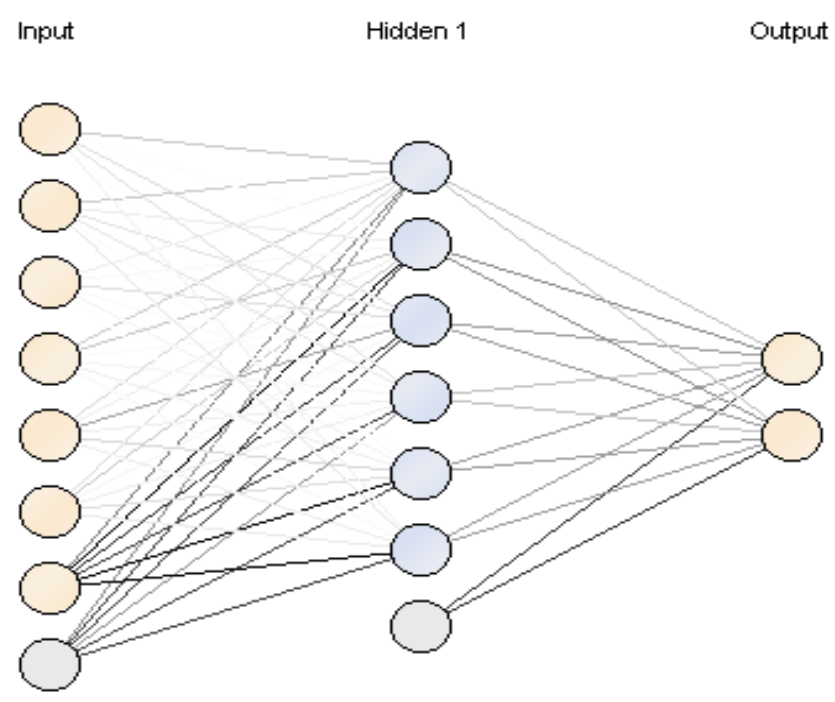

Figure 4. Architectural neural network

\subsection{PSO-based Neural Network Method}

Particle Swarm Optimization has more or more superior performance search for more optimization problems with faster and more stable convergence rates. To find the optimal solution, each particle moves towards its previous best position and the best position globally. The best results of the experiment above are with accuracy produced by 98.85 and AUC of 0.996.

The next step is to select the attributes used for the sexes, the serial number of the political party, the legitimate vote of the party, the number of seats, the electoral district, the legislative candidate number, the legitimate vote of the legislative candidate and 1 attribute as the label that is the result of the election. From the experimental results by using the neural network algorithm based on particle swarm optimization we get attributes that have an effect on attribute weights: Number of seats with weight 0.143 , number of legislative candidates with weight 0.344 and the legislative candidate with weight 1 . While other attributes such as sex, party serial number, the legitimate vote of the party, election area and valid vote of legislative candidate have no effect on attribute weight.

From the best experiments above we get the neural network architecture by producing fifteen hidden layers with two input layer attributes and two output layers. The neural network architecture image is shown in Figure 5 below

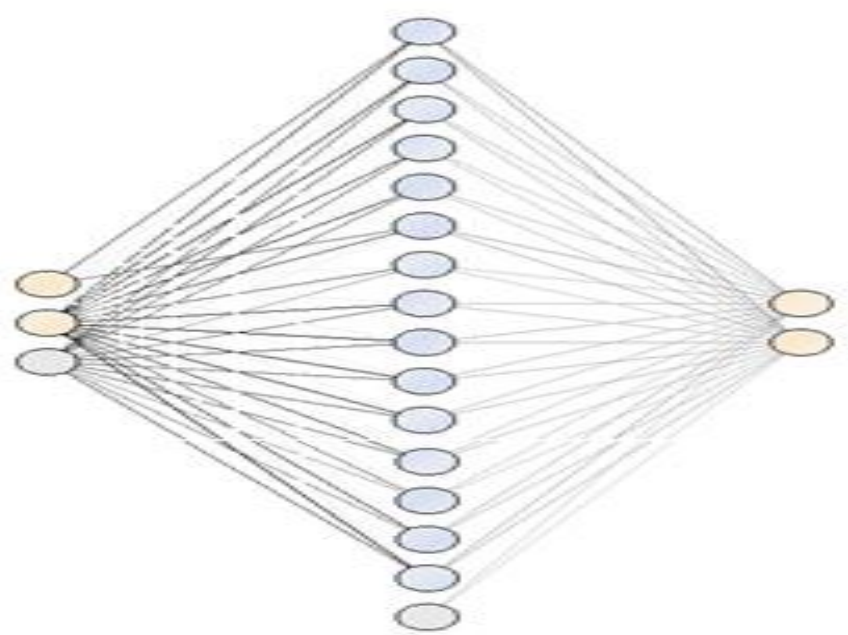

Figure 5. PSO based neural network architecture

\subsection{Neural Network based Genetic Algorithm}

The neural network algorithm can be described as follows: when the network is assigned an input pattern as a training pattern then the pattern goes to the units in the hidden layer to be forwarded to the outermost layer units. While the genetic algorithm is a heuristic search algorithm based on the mechanism of biological evolution. The diversity in biological evolution is a variation of the chromosomes between individual organisms. This chromosome variation will affect the rate of reproduction and the level of the organism's ability to survive. Tests using genetic algorithm based neural network obtained accuracy $93.03 \%$ with $91.28 \%$ precision value and AUC value is 0.971 .

\subsection{Model Evaluation and Validation Analysis}

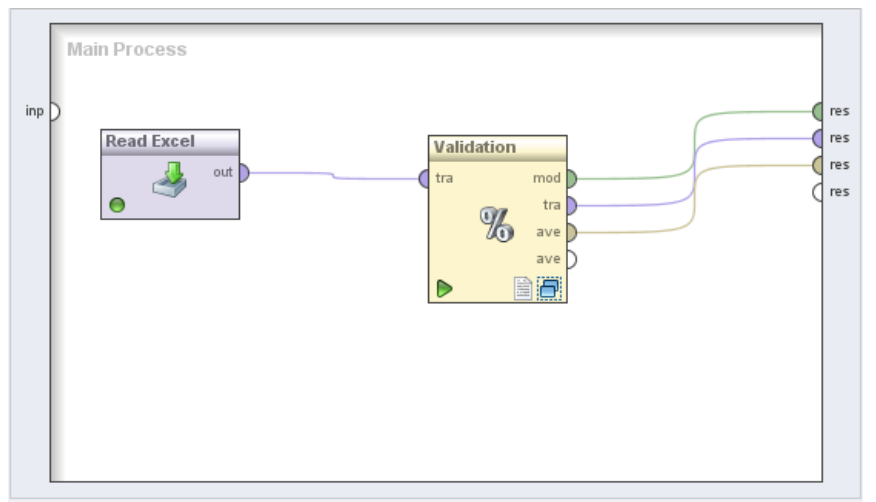

Figure 6. Cross-validation testing 
From the test results in Figure 6 above, both evaluations using confusion matrix and ROC curve proved that the results of algorithm-based neural network algorithm genetic algorithm have a higher accuracy value than neural network algorithm. The accuracy value for the neural network algorithm model is $98.50 \%$ and the accuracy value for the genetic network algorithm based on Genetic Algebra is $93.03 \%$ with the difference of $5.47 \%$ accuracy.

While evaluation using ROC curve that yields value of AUC (Area Under the Curve) to model of artificial neural network algorithm that yield value of 0.982 with the value of diagnosis Excellent Classification, while the algorithm neural network based on genetic algorithms generate value 0971 with a value of diagnosis Excellent Classification and the difference in the value of both of 0.011 .

\section{CONCLUSION}

Based on experimental results conducted from optimization analysis of neural network algorithm model based on genetic algorithm. The resulting model is tested to get accuracy, precision, recall and AUC value of each algorithm so that the test obtained by using neural network obtained accuracy value is $91.64 \%$ with $91.20 \%$ precision value and AUC value is 0.942. while testing using genetic algorithm based neural network obtained accuracy value $93.03 \%$ with $91.28 \%$ precision value and the value of AUC is 0.971. it can be concluded that the testing of Jakarta legislative election model using a neural network with neural network based on genetic algorithm found that neural network testing based on genetic algorithm is better than the neural network itself. Thus from the results of the above model testing can be concluded carrying genetic algorithm-based neural network provides a solution to the legislative election problems of DKI Jakarta more accurate.

\section{ACKNOWLEDGMENT}

We would like to thank our fellow lecturers for a warm discussion on this research. Also for PPPM STMIK Nusa Mandiri, which has supported us to do this research.

\section{REFERENCES}

[1] Sekretariat Negara RI, "Pemilihan Umum Anggota Dewan Perwakilan Rakyat, Dewan Perwakilan Daerah, Dan Dewan Perwakilan Rakyat Daerah," Jakarta, 2008.

[2] S. E. Rigdon, S. H. Jacobson, W. K. Tam Cho, E. C. Sewell, and C. J. Rigdon, "A Bayesian Prediction Model for the U.S. Presidential Election," Am. Polit. Res., vol. 37, no. 4, pp. 700-724, Jul. 2009.

[3] N. H. Sardini, Restorasi penyelenggaraan pemilu di
Indonesia, 1st ed. Jakarta: Fajar Media Press, 2015.

[4] E. D. Astuti, Pengantar Jaringan Saraf Tiruan, 1st ed. Wonosobo: Star Publishing, 2009.

[5] A. Shukla, R. Tiwari, and R. Kala, Real life applications of soft computing. London: CRC Press, 2010.

[6] Kusrini; and E. T. Luthfi, Algoritma Data Mining, 1st ed. Yogyakarta: Penerbit Andi, 2009.

[7] J. Han and M. Kamber, Data mining: Concepts and Techniques, 2nd ed. Elsevier, 2006.

[8] A. Fahad et al., "A Survey of Clustering Algorithms for Big Data: Taxonomy and Empirical Analysis," IEEE Trans. Emerg. Top. Comput., vol. 2, no. 3, pp. 267-279, Sep. 2014.

[9] F. Gorunescu, "Data Mining Techniques and Models," vol. 12, Berlin: Springer, 2011, pp. 185317.

[10] G. J. Myatt and W. P. Johnson, Making Sense of Data I: A Practical Guide to Exploratory Data Analysis and Data Mining, 1st ed. Indianapolis: John Wiley \& Sons, 2014.

[11] O. Maimon and L. Rokach, Data Mining and Knowledge Discovery Handbook. Springer, 2006.

[12] A. Salappa, M. Doumpos, and C. Zopounidis, "Feature selection algorithms in classification problems: an experimental evaluation," Optim. Methods Softw., vol. 22, no. 1, pp. 199-212, Feb. 2007.

[13] T.-S. Park, J.-H. Lee, and B. Choi, “Optimization for Artificial Neural Network with Adaptive inertial weight of particle swarm optimization," in 2009 8th IEEE International Conference on Cognitive Informatics, 2009, pp. 481-485.

[14] Z. Zukhri, Algoritma Genetika Metode Komputasi Evolusioner untuk Menyelesaikan Masalah Optimasi. Yogyakarta: Andi Offset, 2014.

[15] C. Vercellis, Business Intelligence : Data Mining and Optimization for Decision Making. West Sussex: Wiley, 2011.

[16] C. Dawson, Projects in Computing and Information Systems: A Student's Guide, 1st ed. Ottawa: Pearson Education., 2009. 